\title{
Long-term AVHRR SST change analysis in the Taiwan Strait using the rotated EOF method
}

\author{
Yi-Chun $\mathrm{Kuo}^{1,2}$, Ming-An Lee ${ }^{1,2, *}$, Che-Chen Chuang ${ }^{1}$, and Ying-Pu Ma ${ }^{1}$ \\ ${ }^{1}$ Department of Environmental Biology and Fisheries Science, National Taiwan Ocean University, Keelung, Taiwan \\ ${ }^{2}$ Center of Excellence for Oceans, National Taiwan Ocean University, Keelung, Taiwan
}

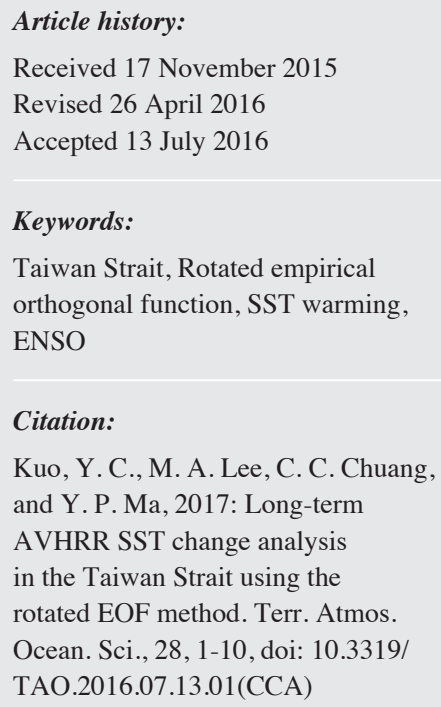

Kuo, Y. C., M. A. Lee, C. C. Chuang, and Y. P. Ma, 2017: Long-term AVHRR SST change analysis in the Taiwan Strait using the rotated EOF method. Terr. Atmos. Ocean. Sci., 28, 1-10, doi: 10.3319/ TAO.2016.07.13.01(CCA)

\begin{abstract}
The Taiwan Strait (TS) connects the East China Sea (ECS) and South China Sea (SCS). Flow circulation in the TS exhibits complicated patterns during winter. The cold China Coastal Current (CCC) flows southward into the northwestern side of the strait as the warm Kuroshio Branch (KB) enters the strait along the southeastern side. In addition to the control that the northeasterly monsoon exerts over the CCC intrusion strength, the complex topography modifies the circulation. The winter temperature gradient in the TS is nearly horizontal. The sea surface temperature (SST) data reveal the main circulation features, including a distinct SST front in the middle of the strait. A rotated empirical orthogonal function (REOF) analysis is applied to the advanced very-high-resolution radiometer data to define four SST regions: the $\mathrm{CCC}$ and $\mathrm{KB}$ sources as well as the regions influenced by the Taiwan Banks and the Chang-Yun Rise. The Mann-Kendall trend detection method indicated that the SST in the TS (except in the KB region) abruptly increased during 1992 - 1994. The warming tendency in the KB region was slower compared with that of the other regions. The relationship between the El Niño-Southern Oscillation phase and SST variation in the TS exhibited spatial and decadal variations. The SST in the northern TS tended to be warmer (cooler) during El Niño (La Niña) years compared with normal years. However, the opposite relationship was found in the southern TS: SST cooling (warming) occurred during El Niño (La Niña) years and this phenomenon existed only after the SST warming regime shift (1992 - 1994).
\end{abstract}

\section{INTRODUCTION}

The Taiwan Strait (TS) connects the East China Sea (ECS) and South China Sea (SCS), and the water flow in the strait is mainly northward because of the pressure gradient associated with large-scale circulation (Chuang 1985, 1986). Northeasterly monsoon winds drive the cold China Coastal Current (CCC), except in winter, which flows southward along the west coast of the TS. The warm Kuroshio Branch (KB) Current enters the TS through the Penghu Channel from the southeast direction (Jan et al. 2002). A distinct topography (Fig. 1) - the Chang-Yun Rise (CYR) - in the middle of the strait restricts water transport in the northsouth direction. The Taiwan Banks (TWB) is located in the southwestern part of the TS and has a depth of less than $30 \mathrm{~m}$. The CYR, TWB, and northeasterly winter monsoon

\footnotetext{
* Corresponding author

E-mail:malee@ntou.edu.tw
}

together lead to the formation of a quasi-permanent front around the northern end of the CYR, and another front at the southern edge of the TWB. The front around the northern end of the CYR separates the CCC and the KB Current. The other front marks the boundary between the coastal waters and the SCS warm water ( $\mathrm{Li}$ et al. 2000; Chang et al. 2006). The horizontal temperature structure during wintertime is crucial because it reflects the advective heat redistribution between the ECS and the SCS. Moreover, the movement of isotherms and the front location are critical indicators of the local fishing grounds and fish species distribution (Chang et al. 2013).

On interannual scales the winter sea surface temperature (SST) in the TS is influenced by the large-scale climate variability resulting from the anomalous monsoon associated with the El Niño-Southern Oscillation (ENSO) in the tropical Pacific. The ENSO-related SST variation is reflected in 
larval anchovy catches (Hsieh et al. 2009). In addition to the climate variability, ocean warming in the ECS and SCS areas has also been identified as a critical area of study. Belkin (2009) observed a high warming of $1.22^{\circ} \mathrm{C}$ in the ECS Large Marine Ecosystem (LME) between 1982 and 2006, and a median warming of $0.44^{\circ} \mathrm{C}$ in the SCS LME. Kuo and Lee (2013) reported that the winter SST warming spatial warming over the past 33 years in the TS was $3^{\circ} \mathrm{C}$. The TS topography can modify the warming trend through its interaction with the water flow associated with different water sources.

The seasonal monsoon transition and changing topography cause the long-term SST changes to vary considerably in space and time. High-resolution SST data and empirical orthogonal function (EOF) analysis can help in efficiently extracting information from spatiotemporally varying physical quantities. Given any space-time meteorological and oceanographic data, EOF analysis observed a set of orthogonal spatial patterns along with the associated temporally varying amplitudes (principal components) (Emery and Thomson 2001). However, because of the orthogonality constraint, the EOF mode patterns are sometimes difficult to physically interpret. For example, a dipole-like EOF mode often appears while the dominant mode is of the same sign over the domain. Physical processes are generally not independent and hence expected to be non-orthogonal. Rotated empirical orthogonal function (REOF) analysis, which involves linear transformations leading EOFs based on rotation, were introduced to overcome this difficulty. REOF can simplify the spatial structure while preserving robust patterns. It can avoid dipole-like EOF patterns that cannot be physically interpreted (Cheng et al. 1995; Hannachi et al. 2006). REOF is particularly useful when the study is focused on the second EOF mode, since it has to be orthogonal to the first mode. REOF analysis might be a better tool for determining the spatiotemporal variation of the long-term SST in the TS. This REOF application has not been reported.

Satellite SST data with a high resolution $(4 \mathrm{~km})$, covering a period of 33 years were used to investigate TS warming in this study. Both EOF and REOF analysis were applied to simplify and quantify the spatiotemporal SST variability. Section 2 briefly introduces the satellite data. Section 3 presents the data analysis results. Section 4 discusses the results and presents concluding remarks.

\section{DATA AND ANALYSIS METHODS}

Daily SST images for the period January 1980 to February 2013 were obtained from Advanced Very-High-Resolution Radiometer (AVHRR) sensors on National Oceanic and Atmospheric Administration (NOAA) satellites (http:// www.class.ngdc.noaa.gov) and the regional AVHRR data library at National Taiwan Ocean University, Keelung, Taiwan. The navigation and cloud detection techniques presented by Sakaida and Kawamura (1992) were used. Daily AVHRR images at least $85 \%$ cloud-free over the study area were collected from December to the following February

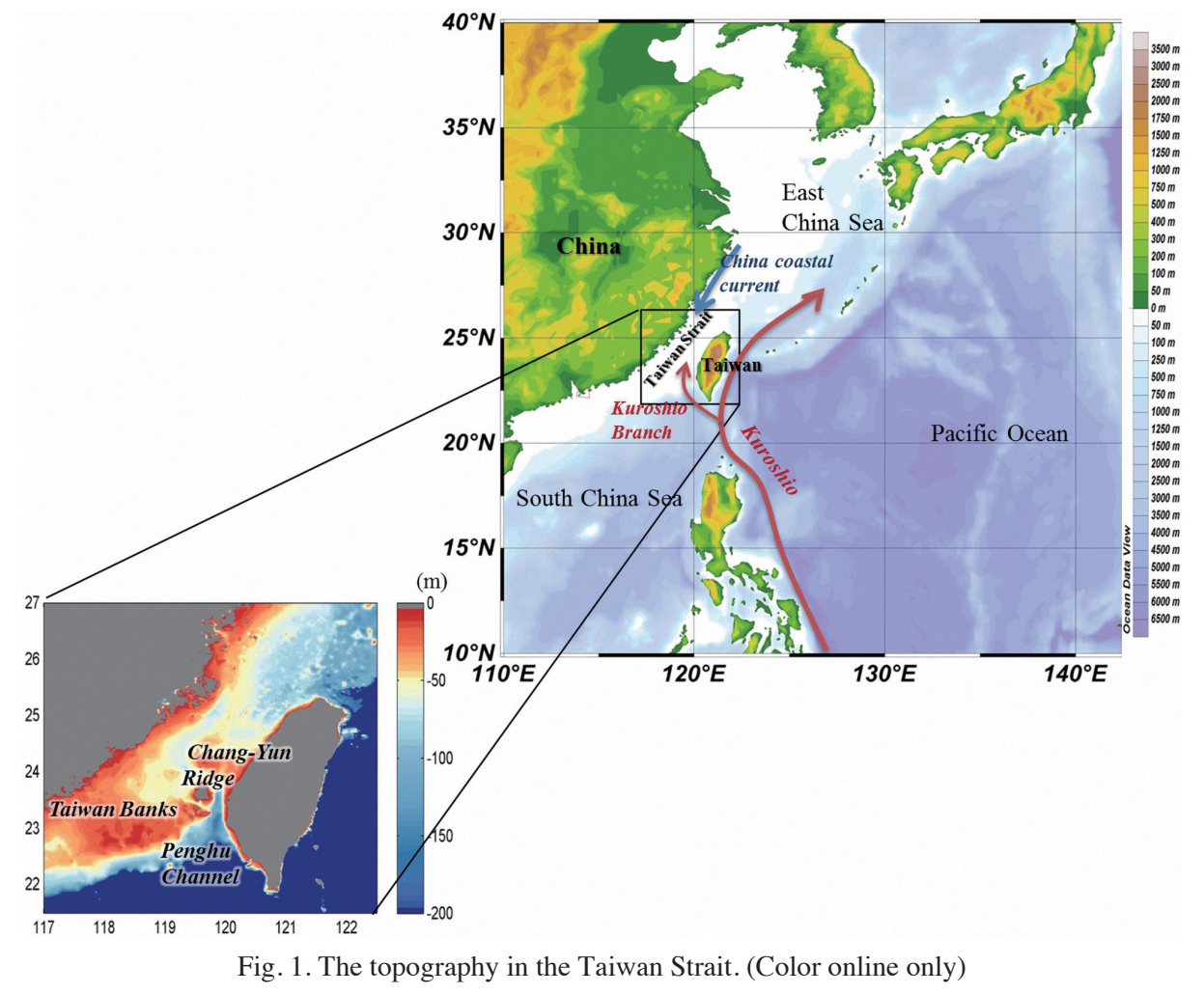


in 1980 - 2013. The multichannel sea surface temperature (MCSST) algorithm (McClain et al. 1985) was used to produce SST images at spatial resolutions of 4 (1980 - 1995) and 1.1 (1996 - 2013). We obtained 6 - 7 images per day at a temporal resolution of approximately $2-3 \mathrm{~h}$. The daily mean MCSST obtained from the satellite differs about $0.21^{\circ} \mathrm{C}$ from surface sea temperature obtained from ship survey in the waters off Taiwan (Lee et al. 2005). Monthly SST data were obtained by arithmetically averaging all available images for each month on a pixel-by-pixel basis (excluding missing data and clouds). The data grids for 1996 - 2013 were merged to a $4 \mathrm{~km} \times 4 \mathrm{~km}$ grid to unify the data resolution. Monthly SST data for a period of 33 years and in the domain between $115-122^{\circ} \mathrm{E}$ and $22-26^{\circ} \mathrm{N}$ with 154173 spatial data points were used to study changes in winter SST patterns in the TS in response to global warming trends and other climatic variations. Notice that six images collected in 1998/1, 2011/1, 2012/1, 1982/2, 1983/2, 2012/2, 1994/12, and 2011/12 were omitted to prevent the results from being biased because the cloud-free pixel coverage of these images was $<85 \%$.

Data on monthly average sea surface wind fields were obtained from the National Centers for Environmental Prediction (reanalysis data; Kalnay et al. 1996). The data are provided by the Earth System Research Laboratory's Physical Sciences Division at NOAA's Office of Oceanic and Atmospheric Research, Boulder, Colorado, USA, through their Web site at http://www.esrl.noaa.gov/psd/data/grid-

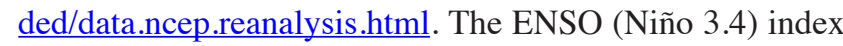
was retrieved from the NOAA Web site (http://www.cpc. noaa.gov). Niño 3.4 is the average SST anomaly in the region bounded by the latitudes $5^{\circ} \mathrm{N}$ and $5^{\circ} \mathrm{S}$ in the longitude range $170-120^{\circ} \mathrm{W}$. To identify warm and cold episodes, NOAA stipulates that the Niño 3.4 SST must be equal to or greater than $0.5^{\circ} \mathrm{C}$ and lower than $-0.5^{\circ} \mathrm{C}$, respectively, for at least three months.

EOF analysis is a statistical method used to decompose a multivariate data set into its principal components. Satellite SST data were ordered in a two-dimensional array in this study for EOF analysis. In other words, they were represented by an $\mathrm{M} \times \mathrm{N}$ matrix $\mathrm{T}(\mathrm{x}, \mathrm{t})$, where $\mathrm{M}$ is the number of elements in the spatial dimension and $\mathrm{N}$ is the number of elements in the temporal dimension. The temporal means were removed to reveal features that varied strongly with time to extract detailed information. The EOF modes were the eigenvectors of the covariance matrix of $\mathrm{T}$, and $\mathrm{T}^{\mathrm{T}} \mathrm{T}$ represented the time averages of the covariance between data at various spatial locations. The covariance matrix was decomposed using the singular value decomposition method. The product $\mathrm{T}^{\mathrm{T}} \mathrm{T}$ can be represented as $\mathrm{VS}^{2} \mathrm{~V}^{\mathrm{T}}$, where the singular values (S) represent the eigenvalues and the eigenvectors $\mathrm{V}$ represent the empirical orthogonal modes. The spatial patterns and time-series variations of SSTs in the eastern TS can then be elucidated (Emery and Thomson
2001). The bulk of variance in a data set can be described using a few orthogonal modes and the corresponding time variation amplitudes (principal components). Such description enables the major properties of the data set to be easily understood.

The leading EOFs in REOF analysis were used to constrain the rotation for maximizing the rotated EOF pattern simplicity criterion. The rotation matrix $\mathrm{R}$ was used for obtaining the REOFs according to the expression $B=U_{m} R$, where $\mathrm{B}$ denotes the REOF modes and $\mathrm{R}$ depends on the type of rotation. Varimax REOF analysis (Kaiser 1958) was used in the current study. A simplicity criterion is maximized in this analysis as follows:

$$
\max \left\{f(B)=\sum_{k=1}^{m}\left[p \sum_{j=1}^{p} b_{j k}^{4}-\left(\sum_{j=1}^{p} b_{j k}^{2}\right)^{2}\right]\right\}
$$

Four EOF modes were used for REOF analysis. Previous studies have shown that REOF analysis can avoid unphysical dipole-like EOF analysis patterns because of the orthogonality constraint. The mode structures obtained were physically meaningful.

The Mann-Kendall (MK) test is a nonparametric test commonly used for detecting the significance of monotonic trends in meteorological time series (Burn and Elnur 2002; Yue et al. 2003). Because this test does not assume any specific data distribution, it is highly recommended for general use by the World Meteorological Organization (Mitchell et al. 1966). The test considers only the relative values of all elements in the series $x_{1}, x_{2}, \ldots, x_{\mathrm{n}}$ to be analyzed. Each term, $p_{i}$, is computed, which denotes the number of terms with values exceeding $x_{i}$ and appearing later in the series. The MK rank statistic $d_{k}$ is then given by

$d_{k}=\sum_{i=1}^{n m} p_{i}(2 \leq k \leq n)$

Under the no trend null hypothesis, the statistic $d_{k}$ is distributed as a normal distribution with the expected value of $E\left(d_{k}\right)$ and the variance $\operatorname{var}\left(d_{k}\right)$ given by

$$
\begin{aligned}
& E\left(d_{k}\right)=k(k-1) / 4 \\
& \operatorname{var}\left(d_{k}\right)=k(k-1)(2 k+5) / 72
\end{aligned}
$$

The statistic index $U F\left(d_{k}\right)$ is estimated as follows:

$$
U F\left(d_{k}\right)=k \frac{\left|d_{k}-E\left(d_{k}\right)\right|}{\sqrt{\operatorname{var}\left(d_{k}\right)}}(k=1,2,3, \ldots, n)
$$

After this, $U B\left(d_{k}\right)$ will be calculated using the same equation but with a reversed series of data, which means that 
the original time series will be $x_{n}, x_{n-1}, \ldots, x_{1}$. The sequential MK test is often used to observe approximate time the change point occurs. An intersection point of forward and backward curves for the test statistic $(U F$ and $U B$ ) located within the confidence interval indicates where the critical point occurred in the analyzed time series.

\section{RESULT}

\subsection{Climatological Pattern}

Figure 2a shows the 33-year-average climatological SST pattern for the months from December to February (some years of insufficient data because of cloud cover were excluded, as listed in section 2). During the northeast monsoon period, the climatological SST in the TS ranges from $12.5-25.5^{\circ} \mathrm{C}$, and the mean SST decreases from December to February. The SST increased spatially to the southeast of the TS, whereas it decreased to the northwest. The SST gradient resulted mainly from the $\mathrm{CCC}$ intrusion along the Chinese coast. The CCC intrusion was high in December and January. An SST front formed by the cold CCC and warm Kuroshio Current emerged in January (Chang et al. 2006) around the western area of the CYR. Southward of the TWB area, cold water $\left(<16^{\circ} \mathrm{C}\right)$ intruded, and another front formed to the southeast of the TWB. The SST front became stronger in February.

\subsection{EOF Result}

EOF spatiotemporal wintertime SST variation analysis results are presented in Figs. 3a and b. The first four modes explain $74 \%$ of the total variance. The first mode explains $61 \%$ of the total variance. A spatially in-phase pattern with higher values on the northern side and along the winter front region can be seen. The corresponding time series for mode 1 (principal component $1, \mathrm{PC} 1$ ) shows an appreciable increasing trend. The period can be divided roughly into two parts. The PC 1 is mostly negative before the winter of 1993 . After 1993, PC 1 is mostly positive. Overall, the increasing tendency is the greatest during the approximate period 1991 - 2001. PC 1 shows an intraseasonal cycle, indicating that the CCC intrusion was enhanced in December and January and that the winter front was moving southeastward. The high interannual SST variation is attributed to the anomalous East Asian monsoon, which can also cause the movement of winter fronts (Kuo and Ho 2004).

The second mode explains $6 \%$ of the total variance and shows a north-south out-of-phase pattern. This mode explains the opposite temperature variations of two major water sources: the China coastal water and $\mathrm{KB}$ water. The monthly temperature variation is distinct. Generally, PC 2 is positive for December and negative for January and February (not shown), suggesting the influx of colder China coastal water and slightly warmer KB water in January and February.
Most of the outstanding PC 2 coincides with strong ENSO events. As indicated by the Niño 3.4 index, El Niño events were dominant features during 1981 - 1999. Overall, the time series of PC 2 shows a decreasing trend over the study period. This trend represents the decreasing SST variance in the CCC region and increasing SST in the KB Current region. The mode 2 spatial pattern was generated because of the orthogonality constraint. Under strong northeasterly monsoon winds, the offshore branch of the $\mathrm{CCC}$ has been found to form a U-shape in the TS and cause SST cooling in the northeastern TS (Liao et al. 2013). Therefore, the mode 2 pattern cannot completely explain the SST variation associated with changes in the northerly wind strength.

Modes 3 and 4 explain $4 \%$ and $3 \%$ of the total variance, respectively. Mode 3 shows a north-south out-of-phase pattern and a positive value in the vicinity of the CYR region. Mode 4 shows a roughly east-west out-of phase pattern in the southern strait. Both modes 3 and 4 do not show any appreciable long-term trend during the data period. However, large fluctuations appear during 1990 - 2000 in both PCs 3 and 4 . The correlations between the Niño 3.4 index and the PCs for the three winter months were calculated separately (Table 1). The only significant correlation (exceeding the 90\% confidence level) was observed for PC 2 in January. The correlation coefficient reached 0.41 , indicating that the ENSO events were associated with different SST variations between the western and eastern TS. The fifth mode contributed less than $2 \%$ of the total variance and was therefore neglected.

Overall, the EOF analysis result showed that the longterm SST variation in the TS was influenced by the ENSO phenomenon and showed a warming trend. REOF analysis was performed to further investigate the spatial and temporal variation associated with ENSO and warming. The analysis results are discussed in the following section.

\subsection{REOF Result}

The four spatial mode patterns (Fig. 3) show the SST variations concentrated in four regions. The physical meanings of the four mode patterns are clear. The mode patterns define the region in which the SST variations are roughly coherent. Modes 1 and 2 represent the two water sources in the TS. Mode 1 explains 35\% of the variance and shows the $\mathrm{CCC}$ region, which has low temperature and salinity. Mode 2 explains $17 \%$ of the variance and shows the Kuroshio intrusion region, which has high temperature and salinity. Modes $3(14 \%)$ and $4(7 \%)$ indicate the influence of the TWBs and the Chang-Yun Ridge, respectively.

The PCs for the REOFs are plotted in Fig. 4. Clearly, all PCs show warming trends. The year-to-year variation in the PCs indicate that the SST variations in the four regions did not show a simple in-phase or out-of-phase relationship. For example, in 1998, appreciable cooling (compared with 

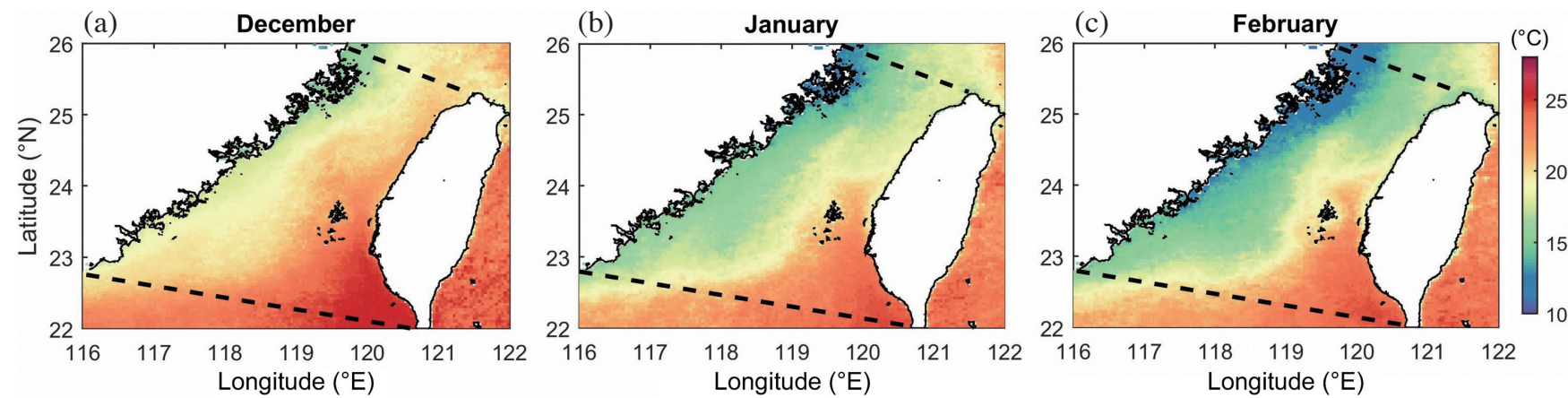

Fig. 2. The climatological mean (1981 - 2013) SST pattern during (a) December, (b) January, and (c) February. Dotted lines show the domain for EOF and REOF analyses. (Color online only)
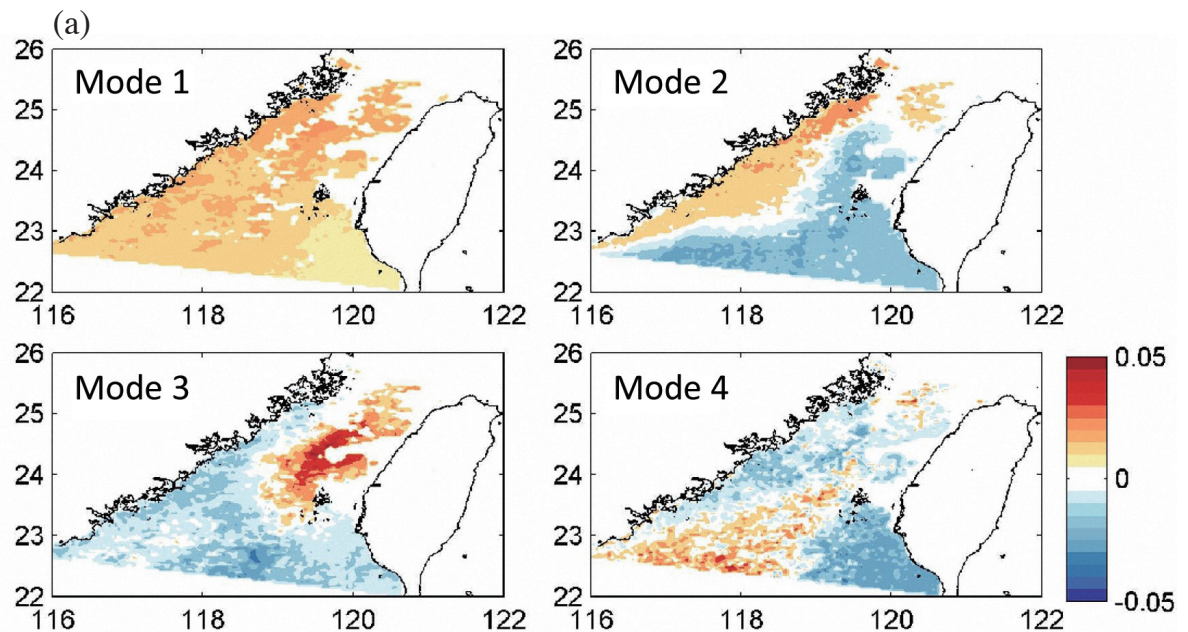

(b)

Niño 3.4
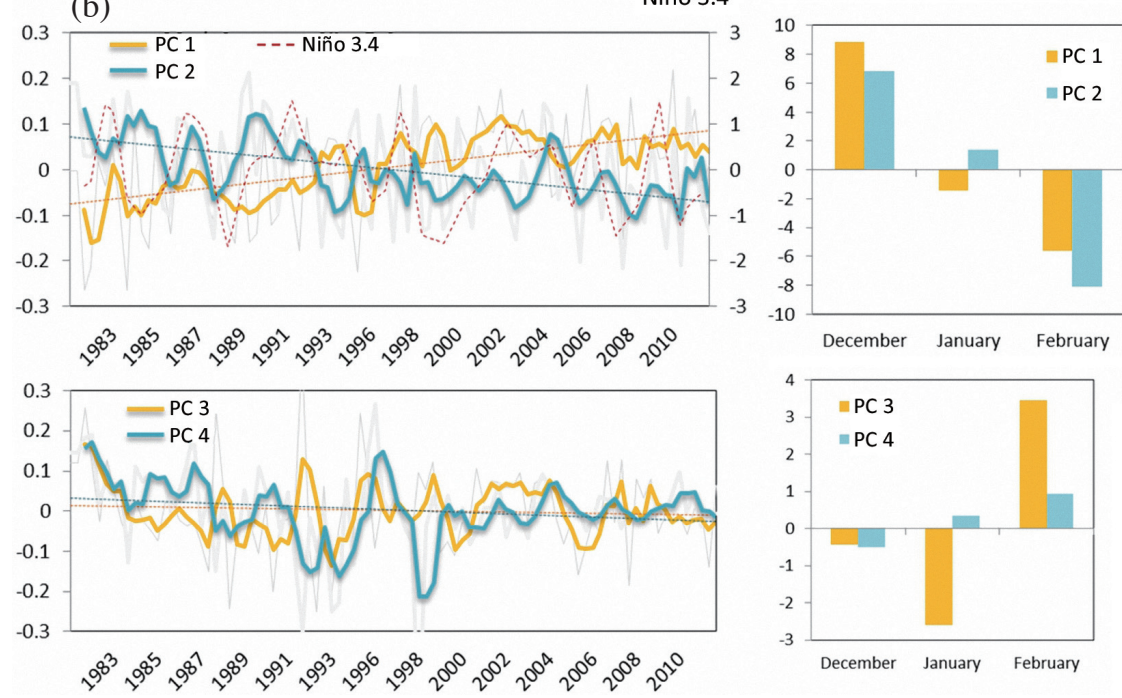

Fig. 3. (a) The EOF1 - EOF4 patterns and (b) their corresponding amplitudes (PCs). The Niño 3.4 was superimposed in (b). (Color online only) 
Table 1. The correlation coefficient between the PCs during December, January, and February and the 3-month Niño 3.4 index centered at December, January, and February, respectively. Confidence level reaching $90 \%$ is marked with ' $*$ '.

\begin{tabular}{cccc}
\hline 1980 - 2013 & December & January & February \\
\hline PC 1 & 0.03 & -0.07 & 0.06 \\
PC 2 & -0.26 & $0.41^{*}$ & 0.31 \\
PC 3 & 0.02 & 0.04 & 0.35 \\
PC 4 & 0.11 & -0.03 & -0.17 \\
\hline
\end{tabular}
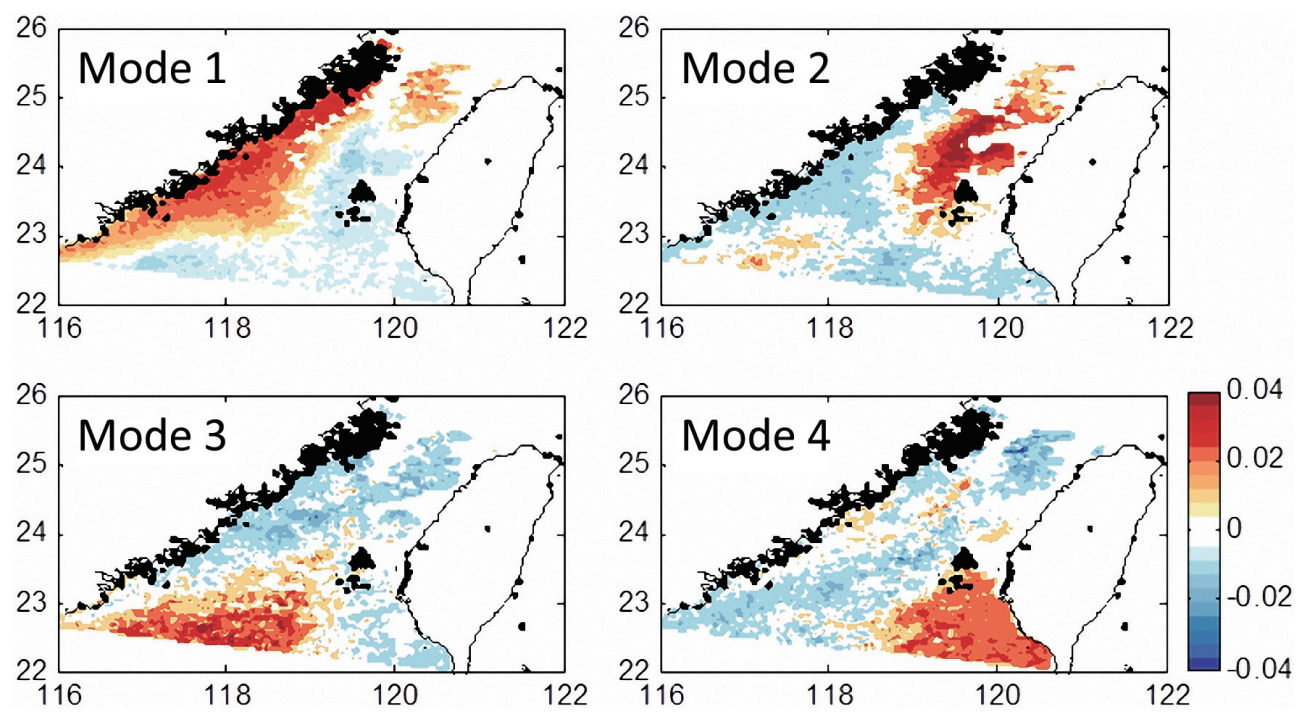

Fig. 4. The spatial patterns of the REOF1 - REOF4. (Color online only)

1997) is observed only in PCs 1 and 2, leading to the inference that the wind stress or wind duration was not sufficient to drive the southward flow that overcomes the obstructing effect of the Chang-Yun Ridge and TWBs. This inference is similar to that of Liao et al. (2013).

The following section presents an analysis of longterm warming phenomena. A linear trend method and the MK test method were used in the analysis.

\subsubsection{MK Test Result}

Among the PCs of the REOFs, PC 1 showed the maximal linear warming trend. The warming trend reached $1.24^{\circ} \mathrm{C} \mathrm{yr}^{-1}$. Figure 5 shows the MK test result, which was conducted to detect potential abrupt changes over the period 1980 - 2013. The intersection of the $U F$ and $U B$ curves is observed in the period $1992-1994$ and it is in the 95\% confidence zone, indicating that PC 1 increased significantly after 1992 - 1994. Before the abrupt change point, PC 1 did not increase significantly at the confidence level of $95 \%$. The linear warming trends for both PCs 2 and 3 showed a warm-

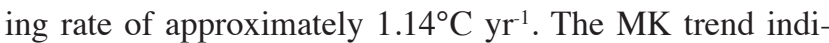
cates that PCs 2 and 3 increased significantly during 1992 - 1994, which roughly corresponds to the period of increase in PC 1. The minimal linear warming trend is observed in PC $4\left(\approx 0.93^{\circ} \mathrm{C} \mathrm{yr}^{-1}\right)$. However, the time at which PC 4 starts to increase significantly (approximately 1988 - 1990) appears to be earlier than that at which the other PCs start to increase. The SST regime shift in the SCS and coastal region around China were related to the ENSO or Pacific Decadal Oscillation phenomenon, as demonstrated by Bao and Ren (2014). The periods 1992 - 1994 and 1988 - 1990 were El Niño periods. The relationship between the SST in the TS and the ENSO phenomenon is discussed in the following section. The SST warming associated with the regime shift related to climate variability is discussed in section 4 .

\subsubsection{Relationship Between SST and ENSO}

Figures $6 \mathrm{a}-\mathrm{c}$ show plots of the PCs obtained from REOF analysis, the monthly Niño 3.4 index, and the normalized monthly sea surface wind speed over the TS (the 

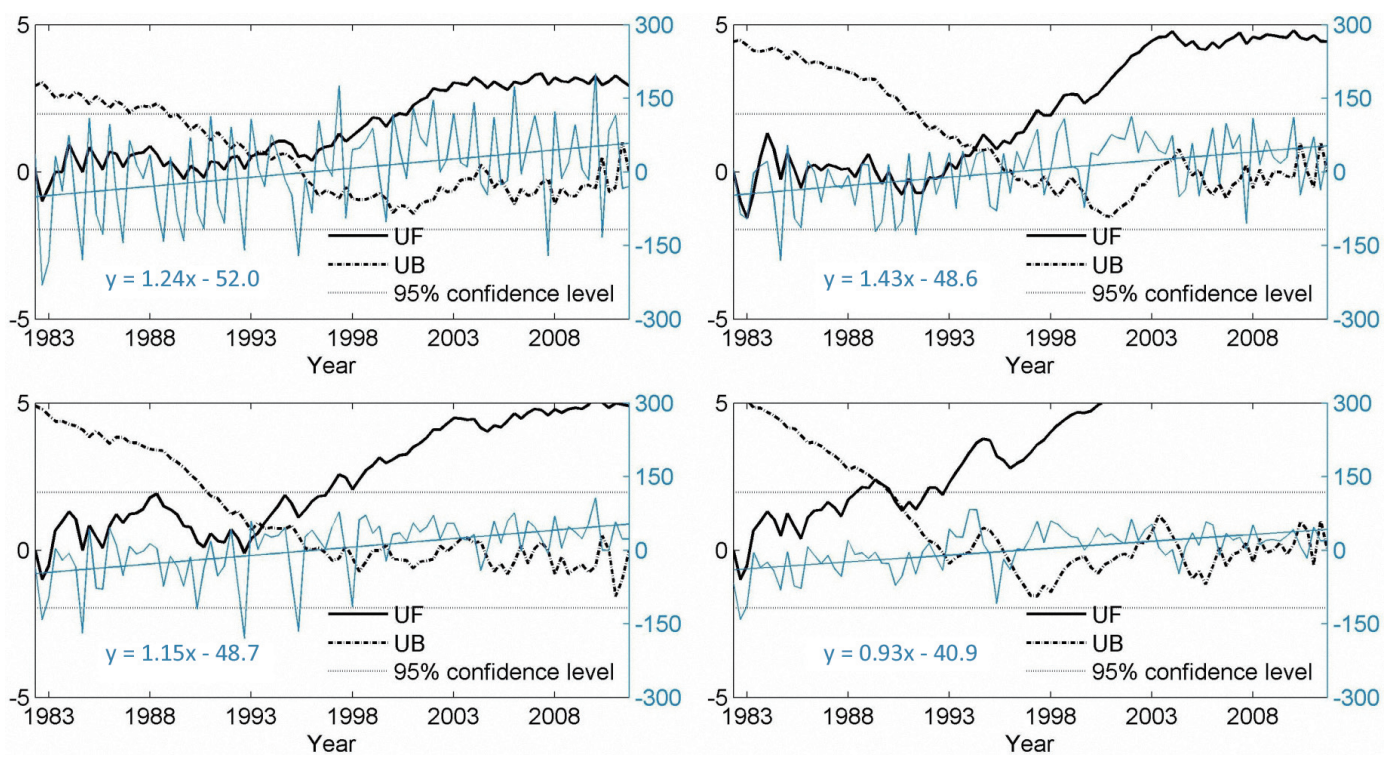

Fig. 5. Time series of PC 1 to PC4 obtained using REOF analysis (black line, left y-axis) and the Mann-Kendall trend of the PCs (blue lines, right y-axis). Detailed information about $U F$ and $U B$ can be obtained from the paper of Ye et al. (2013). (Color online only)

(a) December wind speed (normalised) $\multimap \mathrm{PC} 1$

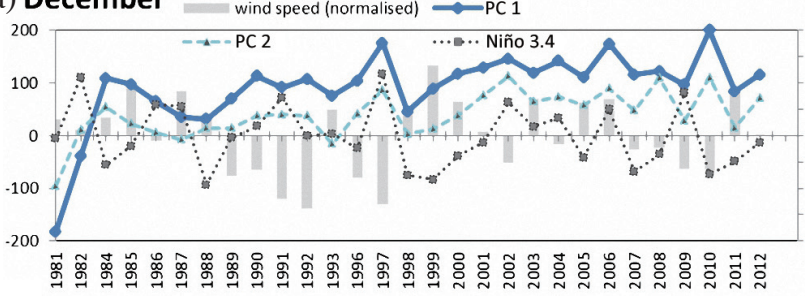

(b) January

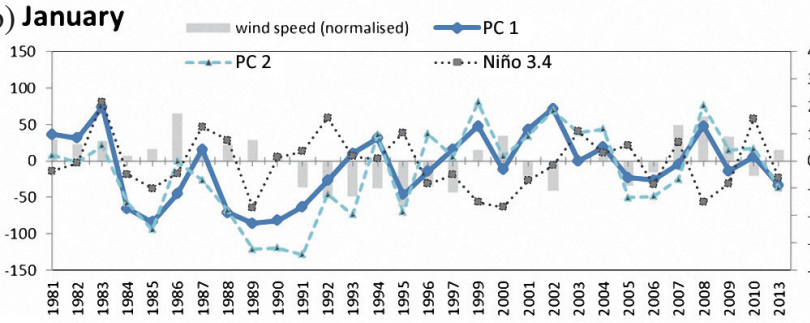

(c) February

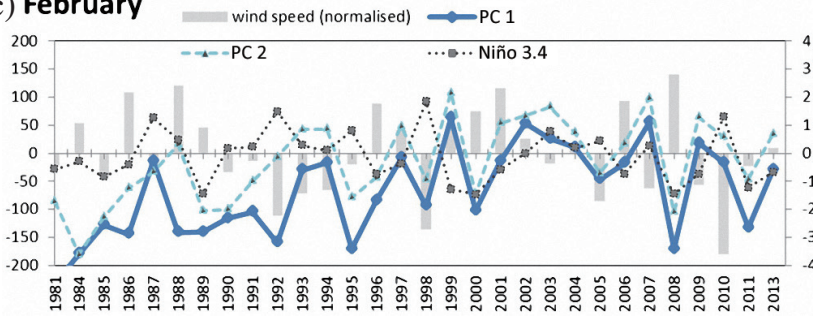

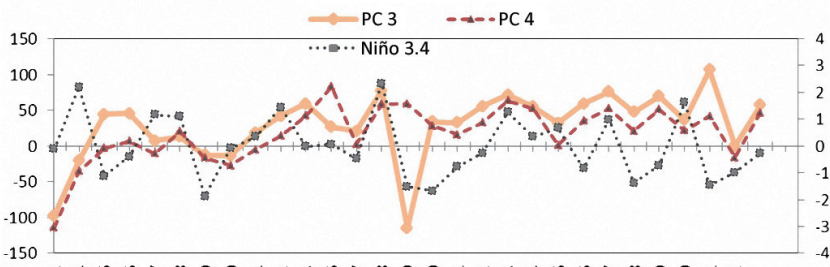

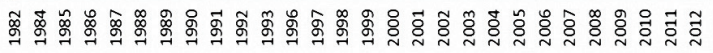
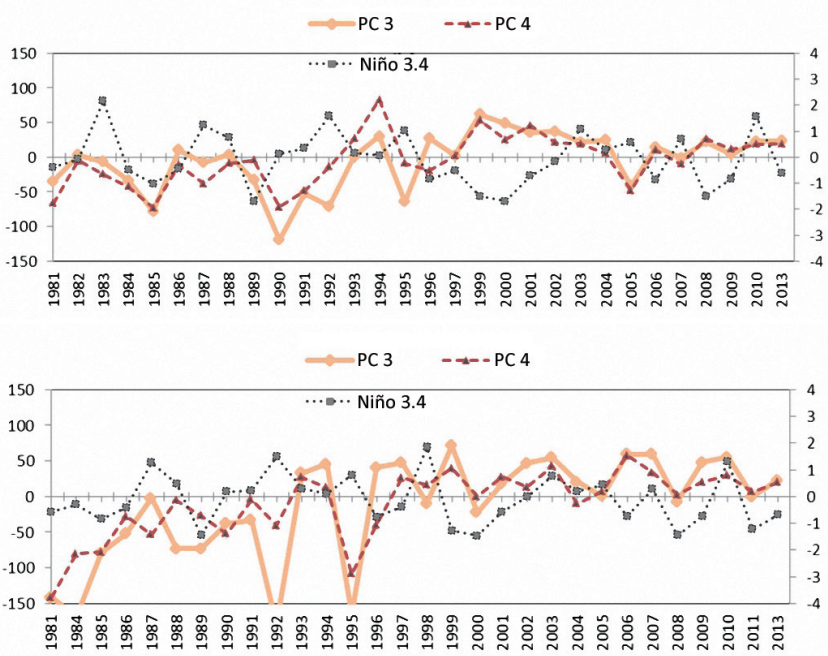

Fig. 6. PCs of the four REOF modes for (a) December, (b) January, and (c) February. The three-month average Niño 3.4 index was centered at December, January, and February, respectively. (Color online only) 
northeasterly monsoon winds) for December, January, and February. A decadal variation in wind speed was observed during the study period. The wind speed was lower during the approximate period 1989 - 1995, which could partially explain the higher SST during this period compared with the SST before 1989 .

The average wind speed was the greatest in December $\left(9.6 \mathrm{~m} \mathrm{~s}^{-1}\right)$, compared with that in January $\left(8.6 \mathrm{~m} \mathrm{~s}^{-1}\right)$ and February $\left(7.3 \mathrm{~m} \mathrm{~s}^{-1}\right)$. However, lower SSTs and the mature wintertime SST phase feature were observed in January and February. The correlation coefficients between the Niño 3.4 index and the wind speed for the three months were -0.38 (December), -0.65 (January), and -0.3 (February). It is reasonable that the in-phase correlation between PC 2 (in the EOF result) and Niño 3.4 is higher in January (Table 1) compared with the correlations in December and February. In Fig. 6, the relationship between PC 2 and Niño 3.4 appears to reverse roughly after 1992, which is also the year of an SST regime shift as indicated by the MK test result (Fig. 5). Figure 7 shows the lagged correlation between the PCs obtained from REOF analysis and the monthly Niño 3.4 index before and after 1992 (correlations reaching the 95\% confidence level are marked with black circles) to determine the relationship between ENSO and the ROEFs. The relationship between ENSO and PCs in December was not significant. Before 1992, PCs 1 and 2 (representing the northern TS regions, respectively) for January and February correlated positively with the Niño 3.4 index from the preceding summer to winter. After 1992, PCs 3 and 4 (representing the southern TS regions) for January and February correlated negatively with the Niño 3.4 index. The Niño 3.4 index in the preceding summer had the strongest correlation with PCs 3 and 4 for January, indicating decadal changes in the relationship between regional SST in the TS and largescale climate variability.

\section{DISCUSSION AND CONCLUSION}

Long-term SST warming in the TS was discussed by Belkin and Lee (2014). They used the climatological data set HadISST1 (spatial resolution: $1^{\circ} \times 1^{\circ}$; total number of grids in the TS: 17) from the UK Met Office Hadley Centre for the period between 1957 and 2011 and showed that SST warming in the TS was considerably enhanced in winter. In addition, the SST warming increased northward. In the present study, SST warming details during 1981 - 2013 were obtained through REOF analysis using high-resolution AHVRR SST data. Four SST regions were defined: the CCC source (mode 1), KB source (mode 4), and regions influenced by the CYR (mode 2) and TWB (mode 3). The REOF analysis result revealed the interannual variation associated with climate variability and decadal warming for the SST regions in the TS. The warming was greater in the CCC region (in the northwestern TS), probably because of a rapidly warming water source in the ECS. The warming rate was considerably greater than that in the SCS and Kuroshio region off Eastern Taiwan.

Belkin and Lee (2014) observed that the SST gradient between the CCC and offshore TS waters abruptly decreased in 1992 and remained low through 2011. The MK trend detection method indicated that during 1992 - 1994, the SST in the TS (except in the KB region) showed an abrupt increase in the SST. In the KB region, an appreciable increase in the SST occurred earlier, during 1988 - 1990. The warming tendency in the KB region was slower compared with the other regions. In particular, during the prevalence of strong northeasterly winds, the SST in the four REOF regions did not always decrease coherently. In certain years, appreciable cooling occurred only in the northern TS, suggesting that the wind stress or wind duration was not sufficient to drive flow that overcomes the obstruction effect by the Chang-Yun (a) lagged correlation between PCs and Nino 3.4 during 1981 - 1991

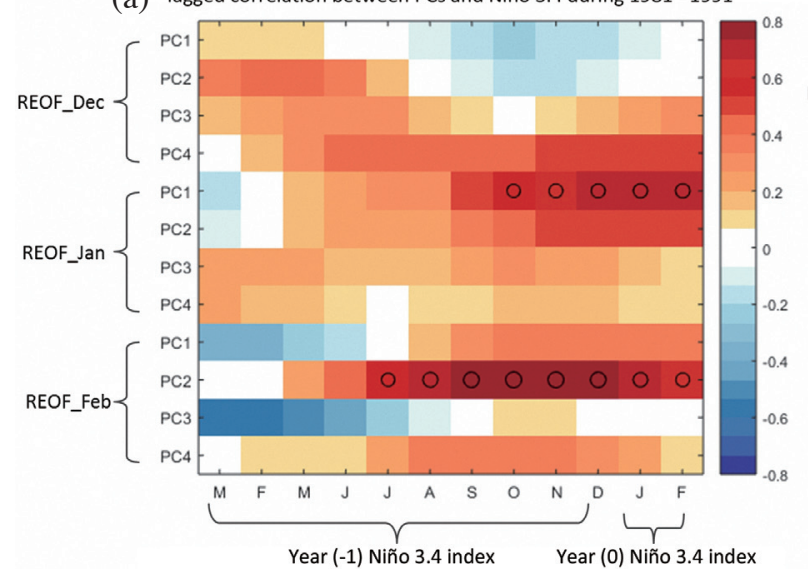

(b) lagged correlation between PCs and Nino 3.4 during $1992-2013$

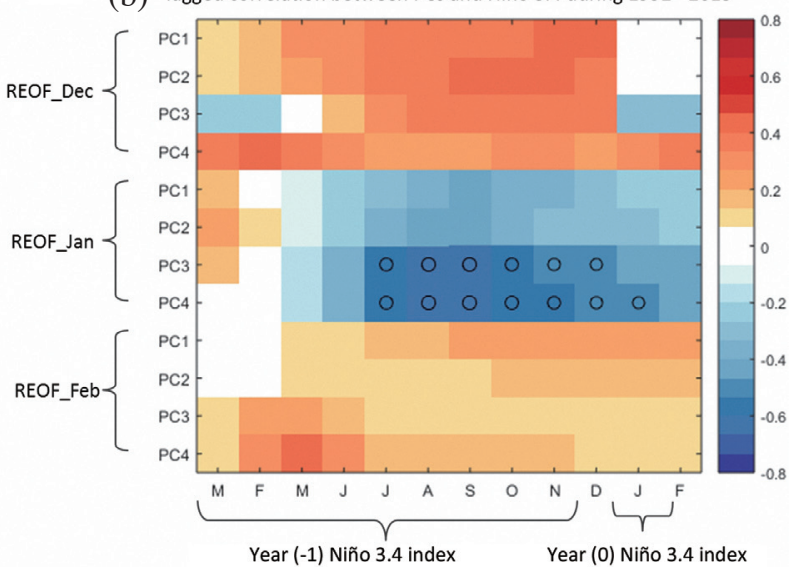

Fig. 7. Lagged correlation for (a) 1981 - 1991 and (b) 1992 - 2013 between the PCs obtained from REOF analysis for December, January, and February and the monthly Niño 3.4 index. The correlation coefficients with a confidence level reaching $95 \%$ are marked with black circles. (Color online only) 
Ridge and TWBs.

The ENSO phenomenon exerts the strongest influence on the East Asian monsoon on interannual timescales (Chang et al. 2004; Kim et al. 2014). Wang et al. (2000) used atmospheric general circulation models and demonstrated that during El Niño (La Niña) years, an anomalous lower-tropospheric anticyclone (cyclone) was formed over the Philippine Sea because of a Rossby wave response to suppressed (enhanced) convective heating. The western North Pacific wind anomalies induced by ENSO events typically develop rapidly in late autumn, and a strong warm event matures in winter. The anomalous anticyclonic (cyclone) circulation reduces the strength of the East Asian winter monsoon. Therefore, the southward intrusion of the cold CCC is stronger during La Niña winters. The northeasterly monsoon over the TS has been reported to be stronger during a La Niña period compared with its strength in normal years. A strong northeasterly monsoon results in appreciable SST cooling in the TS (Kuo and Ho 2004). The EOF and REOF analysis results indicate that the SST in the northern TS during the El Niño (La Niña) tends to be warmer (cooler) than that in normal years. However, after the SST warming regime shift (1992 - 1994), SST cooling (warming) occurred in the southern TS during El Niño (La Niña) years with a weak (strong) northeasterly monsoon wind, particularly in January. Wang and Chern (1989) demonstrated that during wintertime, strong northerly winds drive the China coastal water southward into the TS and that the northward KB water driven by the pressure gradient (associated with large-scale circulation) accumulates and results in down welling because of the conservation of mass (the continuity equation). Therefore, an anticyclonic eddy is formed to the south of the TS. A recent study found that SST warming in the TS was related to the strength of the KB. Oey et al. (2013) suggested that strong winds favor more frequent cross-shelf currents and could cause the heat from the Kuroshio to spread. Wang and Oey (2014) found that the Kuroshio path east of Taiwan has shifted onshore over the past two decades. This phenomenon possibly resulted in enhanced Kuroshio intrusion into the northern SCS and the TS. Overall, the relation between ENSO and the SST variation in the TS showed spatial variation. In addition, the relationship between the ENSO phase and the SST response in the TS showed a decadal variation. Further studies are required to determine whether this decadal variation is associated with long-term SST warming in the TS.

In conclusion, four regions were defined according to their time-space variation. The decadal SST warming in the four regions was estimated and a warming regime shift during 1992 - 1994 was observed. During this regime shift, the relationship between ENSO phase and SST in the TS changed. After the regime shift, stronger northeasterly monsoon enhancing the southward cold coastal current during the cold phase of ENSO (La Niña) caused SST warming in the southern part of the strait, in contrast to SST cooling in the northern part. It is suggested that the interaction between the monsoon and a stronger $\mathrm{KB}$ current is responsible for this phenomenon.

Acknowledgements This study was part of the Taiwan Integrated research program on Climate Change Adaptation Technology (TaiCCAT), sponsored by grants from the National Science Council of Taiwan, MOST 104-2621-M019-001 and 104-2811-M-019-001.

\section{REFERENCES}

Bao, B. and G. Ren, 2014: Climatological characteristics and long-term change of SST over the marginal seas of China. Cont. Shelf Res., 77, 96-106, doi: 10.1016/j. csr.2014.01.013. [Link]

Belkin, I. M., 2009: Rapid warming of Large Marine Ecosystems. Prog. Oceanogr., 81, 207-213, doi: 10.1016/j. pocean.2009.04.011. [Link]

Belkin, I. M. and M. A. Lee, 2014: Long-term variability of sea surface temperature in Taiwan Strait. Clim. Change, 124, 821-834, doi: 10.1007/s10584-0141121-4. [Link]

Burn, D. H. and M. A. H. Elnur, 2002: Detection of hydrologic trends and variability. J. Hydrol., 255, 107-122, doi: 10.1016/S0022-1694(01)00514-5. [Link]

Chang, C. P., Z. Wang, J. Ju, and T. Li, 2004: On the relationship between western maritime continent monsoon rainfall and ENSO during northern winter. J. Climate, 17, 665-672, doi: 10.1175/1520-0442(2004)017<0665 :otrbwm>2.0.co;2. [Link]

Chang, Y., T. Shimada, M. A. Lee, H. J. Lu, F. Sakaida, and H. Kawamura, 2006: Wintertime sea surface temperature fronts in the Taiwan Strait. Geophys. Res. Lett., 33, L23603, doi: 10.1029/2006GL027415. [Link]

Chang, Y., M. A. Lee, K. T. Lee, and K. T. Shao, 2013: Adaptation of fisheries and mariculture management to extreme oceanic environmental changes and climate variability in Taiwan. Mar. Pol., 38, 476-482, doi: 10.1016/j.marpol.2012.08.002. [Link]

Cheng, X., G. Nitsche, and J. M. Wallace, 1995: Robustness of low-frequency circulation patterns derived from EOF and rotated EOF analyses. J. Climate, 8, 17091713, doi: 10.1175/1520-0442(1995)008<1709:ROLF CP>2.0.CO;2. [Link]

Chuang, W. S., 1985: Dynamics of subtidal flow in the Taiwan Strait. J. Oceanographical Soc. Jpn., 41, 65-72, doi: 10.1007/BF02109175. [Link]

Chuang, W. S., 1986: A note on the driving mechanisms of current in the Taiwan Strait. J. Oceanographical Soc. Jpn., 42, 355-361, doi: 10.1007/BF02110430. [Link]

Emery, W. J. and R. E. Thomson, 2001: Data Analysis Methods in Physical Oceanography, second and revised 
edition, Elsevier Science, 658 pp, doi: 10.5670/oceanog.2001.18. [Link]

Hannachi, A., I. T. Jolliffe, D. B. Stephenson, and N. Trendafilov, 2006: In search of simple structures in climate: Simplifying EOFs. Int. J. Climatol., 26, 7-28, doi: 10.1002/joc.1243. [Link]

Hsieh, C. H., C. S. Chen, T. S. Chiu, K. T. Lee, F. J. Shieh, J. Y. Pan, and M. A. Lee, 2009: Time series analyses reveal transient relationships between abundance of larval anchovy and environmental variables in the coastal waters southwest of Taiwan. Fish. Oceanogr., 18, 102117, doi: 10.1111/j.1365-2419.2008.00498.x. [Link]

Jan, S., J. Wang, C. S. Chern, and S. Y. Chao, 2002: Seasonal variation of the circulation in the Taiwan Strait. J. Mar. Syst., 35, 249-268, doi: 10.1016/S09247963(02)00130-6. [Link]

Kaiser, H. F., 1958: The Varimax criterion for analytic rotations in factor analysis. Psychometrika, 23, 187-200, doi: 10.1007/BF02289233. [Link]

Kalnay, E., M. Kanamitsu, R. Kistler, W. Collins, D. Deaven, L. Gandin, M. Iredell, S. Saha, G. White, J. Woollen, Y. Zhu, A. Leetmaa, R. Reynolds, M. Chelliah, W. Ebisuzaki, W. Higgins, J. Janowiak, K. C. Mo, C. Ropelewski, J. Wang, R. Jenne, and D. Joseph, 1996: The NCEP/NCAR 40-year reanalysis project. Bull. Amer. Meteorol. Soc., 77, 437-471, doi: 10.1175/15200477(1996)077<0437:TNYRP>2.0.CO;2. [Link]

Kim, J. W., S. W. Yeh, and E. C. Chang, 2014: Combined effect of El Niño-Southern Oscillation and Pacific decadal oscillation on the East Asian winter monsoon. Clim. Dyn., 42, 957-971, doi: 10.1007/s00382-0131730-z. [Link]

Kuo, N. J. and C. R. Ho, 2004: ENSO effect on the sea surface wind and sea surface temperature in the Taiwan Strait. Geophys. Res. Lett., 31, L13309, doi: 10.1029/2004GL020303. [Link]

Kuo, Y. C. and M. A. Lee, 2013: Decadal variation of wintertime sea surface temperature in the Taiwan Strait. $J$. Mar. Sci. Technol., 21, 117-123, doi: 10.6119/JMST013-1219-9. [Link]

Lee, M. A., Y. Chang, F. Sakaida, H. Kawamura, C. H. Cheng, J. W. Chan, and I. Huang, 2005: Validation of satellite-derived sea surface temperatures for waters around Taiwan. Terr. Atmos. Ocean. Sci., 16, 11891204, doi: 10.3319/TAO.2005.16.5.1189(O). [Link]
Li, L., X. Guo, and R. Wu, 2000: Oceanic fronts in southern Taiwan Strait. J. Oceanogr. Taiwan Strait, 19, 147-156.

Liao, E., Y. Jiang, L. Li, H. Hong, and X. Yan, 2013: The cause of the 2008 cold disaster in the Taiwan Strait. Ocean Model., 62, 1-10, doi: 10.1016/j.oce$\bmod$.2012.11.004. [Link]

McClain, E. P., W. G. Pichel, and C. C. Walton, 1985: Comparative performance of AVHRR based multichannel sea surface temperatures. J. Geophys. Res., 90, 1158711601, doi: 10.1029/JC090iC06p11587. [Link]

Mitchell, J. M., B. Dzerdzeevskii, H. Flohn, W. L. Hofmeyr, H. H. Lamb, K. N. Rao, and C. C. Walléen, 1966: Climatic Change. Technical Note No. 79, Report of a Working Group of the Commission for Climatology, WMO No. 195, 79 pp.

Oey, L. Y., M. C. Chang, Y. L. Chang, Y. C. Lin, and F. H. $\mathrm{Xu}, 2013$ : Decadal warming of coastal China Seas and coupling with winter monsoon and currents. Geophys. Res. Lett., 40, doi: 10.1002/2013GL058202. [Link]

Sakaida, F. and H. Kawamura, 1992: Accuracies of NOAA/ NESDIS sea surface temperature estimation technique in the oceans around Japan. J. Oceanogr., 48, 345-351, doi: 10.1007/BF02233992. [Link]

Wang, B., R. Wu, and X. Fu, 2000: Pacific-East Asian teleconnection: How does ENSO affect East Asian climate? J. Clim., 13, 1517-1536, doi: 10.1175/1520-044 2(2000)013<1517:PEATHD>2.0.CO;2. [Link]

Wang, J. and C. S. Chern, 1989: On cold water intrusions in the eastern Taiwan Strait during the cold season. Acta Oceanographica Taiwanica, 22, 43-67.

Wang, J. and L. Y. Oey, 2014: Inter-annual and decadal fluctuations of the Kuroshio in East China Sea and connection with surface fluxes of momentum and heat. Geophys. Res. Lett., 41, 8538-8546, doi: 10.1002/2014GL062118. [Link]

Ye, X., Q. Zhang, J. Liu, X. Li, and C. Y. Xu, 2013: Distinguishing the relative impacts of climate change and human activities on variation of stream flow in the Poyang Lake catchment, China. J. Hydrol., 494, 8395, doi: 10.1016/j.jhydrol.2013.04.036. [Link]

Yue, S., P. Pilon, and B. Phinney, 2003: Canadian stream flow trend detection: Impacts of serial and cross correlation. Hydrolog. Sci. J., 48, 51-63, doi: 10.1623/ hysj.48.1.51.43478. [Link] 